\title{
Finding the "optimal" size and location of treatment plants for a Jatropha oil plantation project in Thailand
}

\author{
J. E. Everett \\ Emeritus Professor of Information Management, School of Business, \\ The University of Western Australia, Australia
}

\begin{abstract}
Curcas Energy is developing a sustainable energy project in Thailand to produce Jatropha oil as a biological source of diesel fuel. The company is providing Jatropha seeds and advice to smallholder farmers. The crop is being grown as hedgerows on otherwise unused land. The nuts will be transported from widely distributed collection points to central plants where the oil will be extracted. The extraction plants can be any integer multiple of a basic unit, with larger plants having advantages of scale that have to be weighed against the lesser transport costs to smaller more widely distributed treatment plants. This paper describes a modelling tool, developed in Excel, which enables planners to compare the costs and benefits of alternative plant locations and sizes. The collection point locations and estimated production rates are entered into the model, together with potential treatment plant locations, costs and capacities, and transport costs per kilometre. The model computes the preferred plant destination for each collection point, after taking into account production rates and treatment capacities, and plots a map of all the collection points and plants, colour coded to indicate the destination plants for each collection point. The planner can iteratively adjust the plant locations, capacities and costs to explore the wide range of suggested alternatives to be considered.
\end{abstract}

Keywords: transport, sustainable energy, Jatropha, biofuel, Thailand.

\section{Introduction}

Curcas Energy, an Australian company based in Perth, is developing a sustainable energy project to produce Jatropha oil in Thailand. The Jatropha tree 
originated in South America but is now found widely distributed throughout tropical Asia. The trees, which grow to about three metres, can be grown on marginal land, producing poisonous nuts containing about thirty per cent oil. The nuts are often called "candle-nuts", and are used for this purpose in some Asian countries. The oil can be extracted and used as a biological source of diesel fuel $[1,2]$, and provides an excellent feedstock for aviation fuel [3, 4]. The waste can be used for generating electricity or converted into fertiliser or agrichar. Smallholding farmers throughout the country are being supplied with Jatropha seeds and cultivation expertise. It is envisaged that the Jatropha trees will be grown as hedgerows and on wasteland, and will not be using land that could otherwise be used for growing food crops. So, unlike palm oil, the use of Jatropha as a fuel source does not compete with food resources or foodproducing land.

The farmers will deliver their nut crop to local collection points. From the collection points, the nuts will be transported to treatment plants. The treatment plants can be any integer multiple of a basic processing unit. Larger treatment plants can be run at lesser unit cost, but generally involve greater transport distances. This paper describes a modelling tool, developed in Excel, which enables planners to compare the costs and benefits of alternative plant locations and sizes. The collection point locations (northing and easting) and estimated production rates are entered into the model, together with potential treatment plant locations, costs and capacities, and transport costs per kilometre. The model computes the preferred, least-cost feasible, plant destination for each collection point, after taking into account production rates and treatment capacities, and plots a map of all the collection points and plants, colour coded to indicate the destination plants for each collection point. The planner can iteratively adjust the plant locations, capacities and costs to explore the wide range of suggested alternatives to be considered.

The problem could be posed as a linear quadratic problem, or could adapt one of a number of the standard transportation models described in management science textbooks, such as Winston and Albright [5]. However it was chosen to design a heuristic model, realised in Excel using Visual Basic (VBA) coding. This approach has the advantage that the model is readily comprehensible to the user, and adaptable, so that the user can explore the universe of possibilities instead of being constrained to an "optimum" solution which may ignore a range of criteria, not explicit to the model. In the author's experience, this interaction between the user and a heuristic spreadsheet model can greatly facilitate the development of a useful solution, satisfying both the explicit criteria of the model and the user's implicit, sometimes subjective, criteria.

\section{The model}

One frequent criticism of using spreadsheets for computation is that data and computations are not well separated, and equations may be easily overwritten without the user realising. This objection is overcome by using VBA macros instead of placing equations in the cells to carry out the computations. A further 
safeguard is obtained by protecting the workbook, with only the data entry cells being unlocked, so that vital parts of the worksheets cannot be inadvertently overwritten.

The model comprises an Excel workbook with two worksheets. One, named "CollectPts" defines the collection point locations, and reports their allocation to treatment plants. The second worksheet, "Plants", defines the treatment plants and the cost factors, and contains charts reporting the locations and assignments of collection points to treatments plants.

\subsection{Data specification}

The example to be discussed uses hypothetical data, in no way related to the actual cost estimates. The example assumes one hundred collection points, being delivered to a choice of four treatment plant locations, each treatment plant having a chosen number of presses. In practice, multiple alternative treatment plant locations, and varying numbers of presses at each plant, can be chosen to explore the feasible solution domain.

\subsubsection{Collection points}

One line record per collection point on the CollectPts worksheet specifies its name, the northing and easting location in $\mathrm{km}$, and the expected production rate in kilotonnes $(\mathrm{kt})$ per year. Following computation, these records are extended to give the distance to each potential treatment plant destination, and the chosen destination.

\subsubsection{Treatment plants}

One line record per treatment plant on the Plants worksheet specifies its name, the northing and easting location in $\mathrm{km}$, and the number of presses to be installed. Computation cells extend the record to show the plant capacity and costing.

Table 1: $\quad$ Cost and other parameters.

\begin{tabular}{|c|c|c|c|c|}
\hline \# of & Limit & Cap & \multicolumn{2}{|c|}{ Annual Cost } \\
Presses & kt/yr & \$M & \$M/yr & \$/kt \\
\hline 1 & 40 & 5.84 & 1.17 & 1.24 \\
2 & 80 & 9.61 & 1.92 & 1.20 \\
3 & 120 & 13.39 & 2.68 & 1.18 \\
4 & 160 & 17.16 & 3.43 & 1.17 \\
5 & 200 & 20.94 & 4.19 & 1.16 \\
\hline
\end{tabular}

\begin{tabular}{|c|c|}
\hline Transport $/ \mathrm{kt} . \mathrm{km}$ & $\$ 150$ \\
\hline Distance factor & $140 \%$ \\
\hline Cost of Cap/yr & $12 \%$ \\
\hline
\end{tabular}

\subsubsection{Cost and other parameters}

Table 1 shows the cost and other parameters to be specified on the Plants worksheet. The treatment plants are modular, with the production limit or capacity proportional to the number of presses, but with the capital cost increasing rather less than linearly with the number of presses, and the cost per kt 
declining as the number of presses are increased. The cost of transporting a kt of nuts for one $\mathrm{km}$ is also to be specified, along with the yearly cost of capital (enabling capital and running costs to be combined for evaluation). The distance factor will be discussed below.

\subsubsection{Travel distances}

The distances from collection points to treatment plants are unknown, and infeasible to ascertain for the vast number of routes being considered. However, Thailand is well endowed with minor roads, which are not generally straight linkages, so the distance from any collection point to a treatment plant is assumed to be a factor (for example 140\%) multiplied by the straight-line distance.

The straight-line distance is calculated as the Pythagorean hypotenuse, or the square root of the summed squared northing and easting distances.

\subsection{Computation}

Computation comprises two steps, which may then be further iterated with user interaction. Pressing the "Compute Inflow" button and the "Revise Routes" button respectively initiate the computation steps. Each of these buttons runs VBA macros, to carry out the computations described below.

\subsubsection{Compute Inflow}

The Compute Inflow macro extends the collection point records (on the CollectPts worksheet) to report the distance to each plant, and identifies the nearest plant.

Table 2: $\quad$ The initial computed inflow.

\begin{tabular}{|c|c|c|c|c|c|c|c|c|c|c|c|c|c|c|}
\hline Point & \multicolumn{4}{c|}{$\mathrm{km}$} & \multicolumn{4}{c|}{$\mathrm{km}$ to Plant } & \multicolumn{2}{c|}{ Near } & \multicolumn{2}{c|}{ Send to } & \multicolumn{3}{|c|}{ Next Best } \\
Name & $\mathrm{N}$ & $\mathrm{E}$ & $\mathrm{kt} / \mathrm{yr}$ & $\mathrm{A}$ & $\mathrm{B}$ & $\mathrm{C}$ & $\mathrm{D}$ & Plant & Plant & $\mathrm{km}$ & Plant & $\mathrm{km}$ & Extra \\
\hline Col00 & 31 & 61 & 1.95 & 45 & 44 & 50 & 73 & $\mathrm{~B}$ & $\mathrm{~B}$ & 44 & & & \\
Col01 & 51 & 16 & 4.37 & 64 & 48 & 36 & 98 & $\mathrm{C}$ & $\mathrm{C}$ & 36 & & & \\
Col02 & 76 & 99 & 3.05 & 57 & 122 & 85 & 27 & $\mathrm{D}$ & $\mathrm{D}$ & 27 & $\mathrm{~A}$ & 57 & 30 \\
Col03 & 29 & 30 & 2.54 & 63 & 13 & 45 & 99 & $\mathrm{~B}$ & $\mathrm{~B}$ & 13 & & & \\
Col04 & 79 & 69 & 4.40 & 26 & 98 & 49 & 15 & $\mathrm{D}$ & $\mathrm{D}$ & 15 & $\mathrm{~A}$ & 26 & 11 \\
Col05 & 79 & 74 & 1.68 & 30 & 102 & 55 & 8 & $\mathrm{D}$ & $\mathrm{D}$ & 8 & $\mathrm{~A}$ & 30 & 22 \\
Col06 & 13 & 97 & 1.84 & 87 & 92 & 103 & 96 & $\mathrm{~A}$ & $\mathrm{~A}$ & 87 & & & \\
Col07 & 6 & 12 & 0.90 & 104 & 34 & 85 & 140 & $\mathrm{~B}$ & $\mathrm{~B}$ & 34 & & & \\
\hline
\end{tabular}

The implied load to each plant is computed, and compared with the plant's capacity limit. For each collection point initially assigned to an overloaded treatment plant, the next nearest treatment plant is identified, and the extra distance required to get there is reported.

Table 2 shows the top part of the report after computing the inflow. In this example, plant $\mathrm{D}$ is overloaded, so the collection points nearest to plant $\mathrm{D}$ are 
each provided with a "next best" plant and the extra distance that would be incurred if they went there, instead of to the nearest plant. Of the collection points shown, Col02, Col04 and Col05 are each closest to plant D, with plant A being their next closest. Col02 is $27 \mathrm{~km}$ from its nearest plant D, and $57 \mathrm{~km}$ from the next nearest plant $\mathrm{A}$, so an extra $30 \mathrm{~km}$ would be required to go to plant $\mathrm{A}$ instead of plant D.

\subsubsection{Revise routes}

If, as in this case, the initial computed inflow overloads one or more plants, then either the number of presses at those plants can be increased, or some of the collection points going there can be rerouted, by pressing the Revise Routes button.

During the Revise Routes operation, the collection point list is sorted to put those collection points going to the overloaded plant (or plants) at the top, sorted in increasing extra distance that would be incurred if they were rerouted to the next nearest plant. This extra distance can be considered an opportunity cost of re-routing.

Working down the list, the collection points are reassigned to the next nearest plant until the plant overload has been removed. In this case, plant D was overloaded by $15.48 \mathrm{kt} / \mathrm{yr}$, so the top five candidates were rerouted to plant $\mathrm{A}$, as shown in Table 3.

Table 3: $\quad$ Rerouting from the overloaded plant.

\begin{tabular}{|c|c|c|c|c|c|c|c|c|c|c|c|c|c|}
\hline \multicolumn{4}{|c|}{ Point $\mathrm{km}$} & \multicolumn{4}{|c|}{$\mathrm{km}$ to Plant } & \multirow{2}{*}{$\begin{array}{l}\text { Near } \\
\text { Plant }\end{array}$} & \multicolumn{2}{|c|}{ Send to } & \multicolumn{3}{|c|}{ Next Best } \\
\hline Name & $\mathrm{N}$ & E & $\mathrm{kt} / \mathrm{yr}$ & A & B & C & $\mathrm{D}$ & & Plant & $\mathrm{km}$ & Plant & $\mathrm{km}$ & Extra \\
\hline Col97 & 46 & 92 & 3.71 & 51 & 92 & 76 & 50 & D & A & 50 & A & 51 & 1 \\
\hline Col80 & 97 & 54 & 2.69 & 49 & 113 & 56 & 44 & D & A & 44 & A & 49 & 5 \\
\hline Col50 & 50 & 97 & 3.91 & 55 & 100 & 81 & 48 & D & A & 48 & A & 55 & 7 \\
\hline Col89 & 94 & 58 & 0.93 & 44 & 110 & 55 & 36 & D & A & 36 & A & 44 & 8 \\
\hline Col04 & 79 & 69 & 4.40 & 26 & 98 & 49 & 15 & D & A & 15 & A & 26 & 11 \\
\hline Col91 & 99 & 62 & 0.97 & 51 & 119 & 63 & 37 & D & D & 37 & A & 51 & 14 \\
\hline Col82 & 97 & 63 & 2.44 & 47 & 116 & 61 & 33 & D & D & 33 & A & 47 & 14 \\
\hline Col05 & 79 & 74 & 1.68 & 30 & 102 & 55 & 8 & D & D & 8 & A & 30 & 22 \\
\hline Col64 & 73 & 81 & 3.92 & 33 & 101 & 60 & 10 & D & D & 10 & A & 33 & 23 \\
\hline Col58 & 87 & 74 & 3.61 & 40 & 111 & 61 & 13 & D & D & 13 & A & 40 & 27 \\
\hline
\end{tabular}

The list is then re-sorted, as shown in Figure 4. Note that Col04 has been rerouted from plant D to go now to plant A. But Col02 and Col05 still go to plant $\mathrm{D}$, because enough other collection points, with lesser opportunity cost in terms of extra distance, can be re-routed to eliminate the plant overload.

It is possible that, after the above redistribution, some plants will still be overloaded. The Revise Routes operation can be repeated as many times as needed, until all the overloading has been eliminated, provided the total plant capacity exceeds the total collection point production. 
Table 4: $\quad$ The revised routes.

\begin{tabular}{|c|c|c|c|c|c|c|c|c|c|c|c|c|c|}
\hline Point & \multicolumn{4}{c|}{$\mathrm{km}$} & \multicolumn{4}{c|}{$\mathrm{km}$ to Plant } & Near & \multicolumn{2}{c|}{ Send to } & \multicolumn{2}{|c|}{ Next Best } \\
Name & $\mathrm{N}$ & $\mathrm{E}$ & $\mathrm{kt} / \mathrm{yr}$ & $\mathrm{A}$ & $\mathrm{B}$ & $\mathrm{C}$ & $\mathrm{D}$ & Plant & Plant & $\mathrm{km}$ & Plant & $\mathrm{km}$ & Extra \\
\hline Col00 & 31 & 61 & 1.95 & 45 & 44 & 50 & 73 & B & B & 44 & & & \\
Col01 & 51 & 16 & 4.37 & 64 & 48 & 36 & 98 & C & C & 36 & & & \\
Col02 & 76 & 99 & 3.05 & 57 & 122 & 85 & 27 & D & D & 27 & & & \\
Col03 & 29 & 30 & 2.54 & 63 & 13 & 45 & 99 & B & B & 13 & & \\
Col04 & 79 & 69 & 4.40 & 26 & 98 & 49 & 15 & D & A & 26 & & \\
Col05 & 79 & 74 & 1.68 & 30 & 102 & 55 & 8 & D & D & 8 & & \\
Col06 & 13 & 97 & 1.84 & 87 & 92 & 103 & 96 & A & A & 87 & & & \\
Col07 & 6 & 12 & 0.90 & 104 & 34 & 85 & 140 & B & B & 34 & & \\
\hline
\end{tabular}

\subsection{Results}

When a feasible acceptable route allocation has been achieved, tabular and graphical reports of the cost and allocation results can be seen on the Plants worksheet.

\subsubsection{Cost results}

Table 4 shows the cost result report. The number or locations of treatment plant, or the number of presses assigned to each, can be changed and the program rerun to explore the solution domain.

Table 5: $\quad$ Cost results.

\begin{tabular}{|c|c|c|c|c|c|c|c|c|c|c|c|c|c|}
\hline \multirow{2}{*}{$\begin{array}{c}\text { Plant } \\
\text { Name }\end{array}$} & \multicolumn{2}{|c|}{ Locatio } & \multirow{2}{*}{$\begin{array}{l}\# \text { of } \\
\text { Press }\end{array}$} & \multirow{2}{*}{$\begin{array}{l}\text { Limit } \\
\mathrm{kt} / \mathrm{yr}\end{array}$} & \multirow{2}{*}{$\begin{array}{c}\text { Capital } \\
\$ M \\
\end{array}$} & \multicolumn{4}{|c|}{ Annual Plant Operating Cost } & \multicolumn{2}{|c|}{ Inflow/yr } & \multirow{2}{*}{$\begin{array}{l}\text { Truck } \\
\$ M / y r\end{array}$} & \multirow{2}{*}{$\begin{array}{l}\text { Limit } \\
\text { Used }\end{array}$} \\
\hline & $\mathrm{N}$ & $\mathrm{E}$ & & & & Fix\$M & $\$ / \mathrm{kt}$ & Var\$M & Tot $\$ M$ & $\mathrm{kt}$ & kt.km & & \\
\hline $\mathrm{A}$ & 63 & 60 & 2 & 80 & 9.61 & 1.92 & $\$ 1.20$ & 84.97 & 86.89 & 71 & 3,562 & 0.53 & $89 \%$ \\
\hline B & 20 & 32 & 3 & 120 & 13.39 & 2.68 & $\$ 1.18$ & 128.16 & 130.84 & 109 & 4,505 & 0.68 & $91 \%$ \\
\hline $\mathrm{C}$ & 60 & 40 & 2 & 80 & 9.61 & 1.92 & $\$ 1.20$ & 87.04 & 88.97 & 73 & 2,397 & 0.36 & $91 \%$ \\
\hline \multirow[t]{3}{*}{$\mathrm{D}$} & 80 & 80 & 1 & 40 & 5.84 & 1.17 & $\$ 1.24$ & 49.40 & 50.57 & 40 & 699 & 0.10 & $100 \%$ \\
\hline & \multicolumn{2}{|c|}{ Total } & 8 & 320 & 38.46 & 7.69 & $\$ 1.20$ & 349.58 & 357.27 & 292 & 11163 & 1.67 & $91 \%$ \\
\hline & \multicolumn{3}{|c|}{ Total Inflow } & 292 & & & & & & & & & \\
\hline
\end{tabular}

\subsubsection{Allocation results}

Figure 1 plots the locations of the collection points and of the treatment plants, and identifies the treatment plant allocated for each collection point.

Figure 2 shows the capacity limit for each plant, and the total yearly tonnage allocated to it. It also shows the tonnage redistributed from plant D to plant A, to remove the initial overloading.

\section{Discussion}

The example discussed has shown how an Excel workbook, backed up by VBA macros, can be used as a decision tool for a complex transportation problem. 


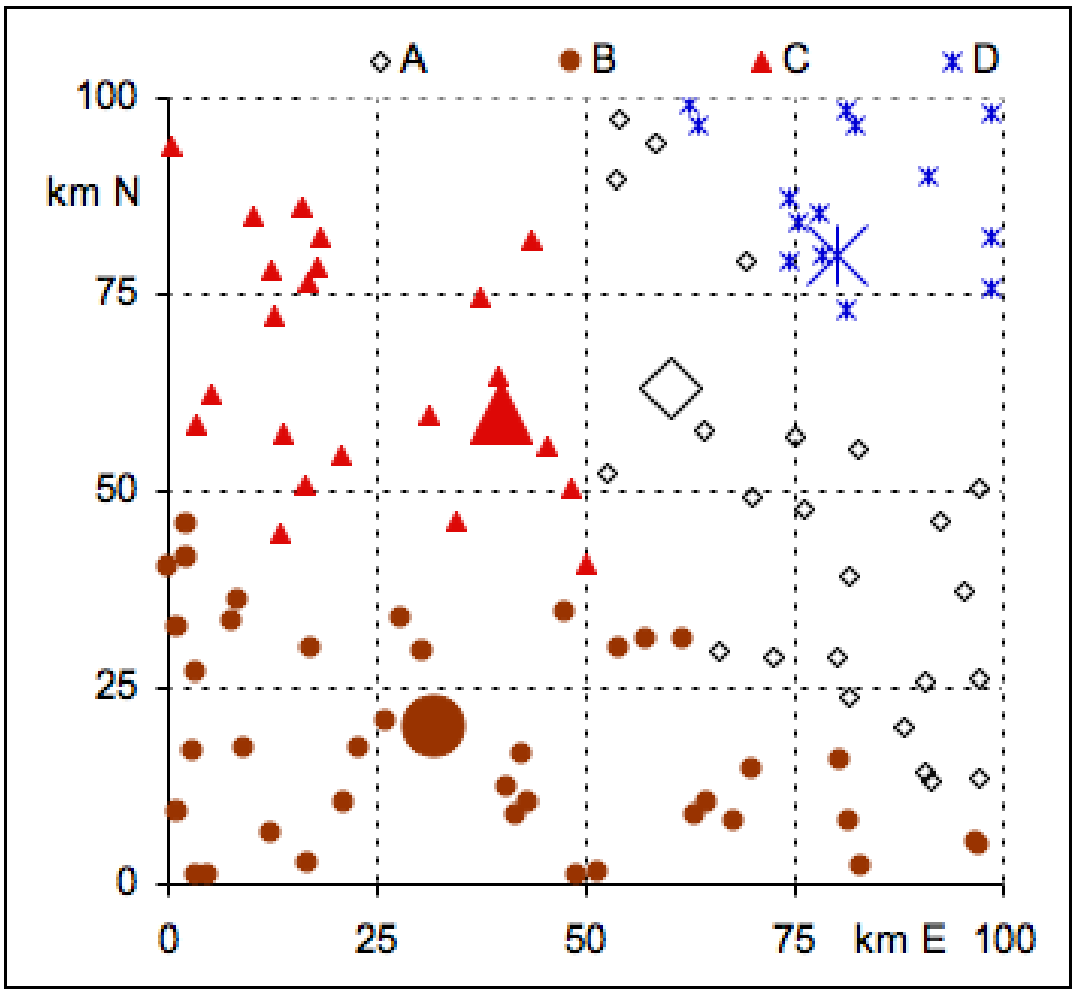

Figure 1: $\quad$ Allocation of collection points to treatment plants.

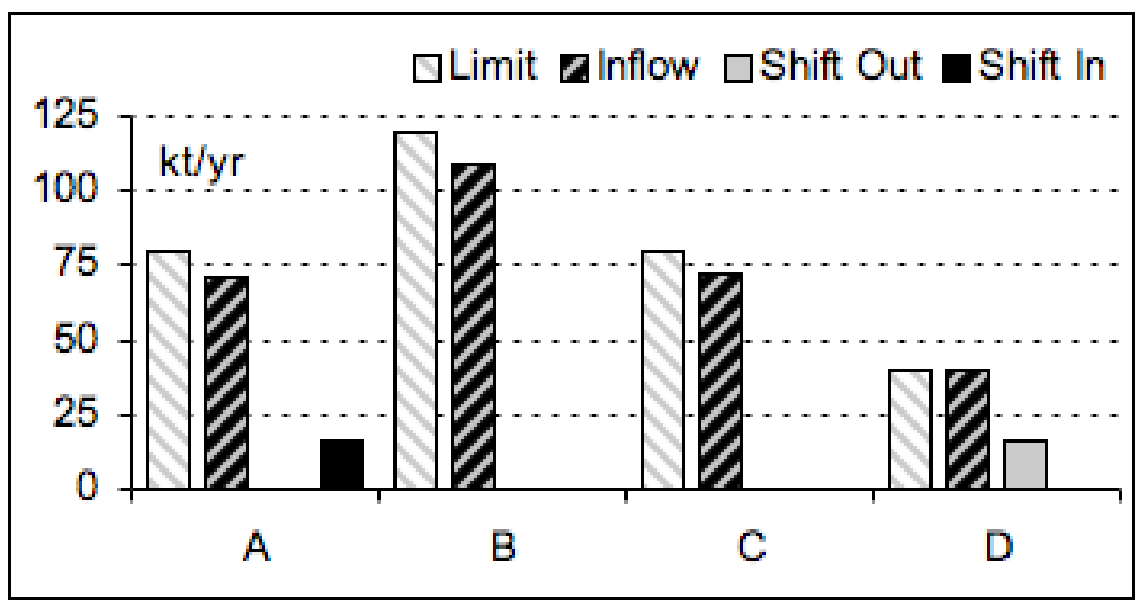

Figure 2: $\quad$ Redistribution to plant A from overloaded plant D to plant A. 
The problem could probably have been recast as a quadratic optimisation to identify a unique optimum. However, it is argued that doing so would reduce the solution space and ignore any non-quantified criteria. In practice, it is found that a spreadsheet-based tool as described here provides opportunity for fruitful human-machine interaction, allowing the computer to do the tedious calculations whilst still enabling the human to include judgemental, not directly quantifiable, factors, and to explore the wide range of possible alternative policies.

\section{References}

[1] Poison plant could help to cure the planet, Times Online, 28 July 2007.

[2] Fitzgerald M., India's Big Plans for Biodiesel, Technology Review, MIT: Cambridge, MA, December 2006.

[3] Air NZ biofuel test flight a success http://tvnz.co.nz/technology-news/air-nzbiofuel-test-flight-success-2431806.

[4] More to noxious weed fuel than meets the sky, The Australian, 5 December 2008.

[5] Winston, W.L. \& Albright, S.C., Practical Management Science, Duxbury: Pacific Grove, CA, pp 193-200, 2001. 